\title{
Reasons for Debt Specialization: Understanding the Perspectives of Small and Large Organizations
}

\author{
Kanwal Iqbal Khan*, Faisal Qadeer**, Shahid Mahmood***, \\ Sayyid Salman Rizavi****
}

\begin{abstract}
Debt specialization (DS) has become a widespread phenomenon among the organizations during the recent years. However, the reasons for its existence and prevalence are yet to be fully known especially among small and large firms. This paper aims to empirically find whether small and large companies pursue DS strategy for similar reasons or different ones. We have used seven years panel data from 2009-2015 for 419 non-financial companies of Pakistan, listed on Pakistan Stock Exchange. The results of comparative analysis confirm the existence of DS across organizations. Small firms follow it to reduce expected bankruptcy cost, for economizing information asymmetry, decreasing agency conflicts and due to limited ingress to the debt market. While large companies include fewer types of debt to reduce operational risk, flotation cost and for building a good reputation. We suggest several theoretical justifications for these results based on trade-off and agency cost theory. Our findings will make a considerable contribution to the evolving debate of reasons for DS and provide new direction to the future scholars.
\end{abstract}

Keyword: Debt specialization, Bankruptcy cost, Information asymmetry, Agency conflicts, Operational risk

JEL Codes: G32, G33, 38

*Assistant professor, Institute of Business \& Management, University of Engineering \& Technology, Lahore.

**Associate Professor, Lahore Business School, The University of Lahore.

*** Lecturer, Department of Commerce, The Islamia University of Bahawalpur, Bahawalpur.

****Associate Professor, Hailey College of Commerce, University of the Punjab. 